\title{
Geochemical fractionation of hazardous elements in fresh and drilled weathered South African coal fly ashes
}

S. A. Akinyemi, W. M. Gitari, R. Thobakgale, L. F. Petrik, B. B.

Nyakuma, J. C. Hower, C. R. Ward, M. L. S. Oliveira \& L. F. O. Silva

\begin{abstract}
The chemical reactions of dry-disposed ash dump, ingressed oxygen, carbon dioxide, and infiltrating rainwater affect mineralogical transformation, redistribution, and migration of chemical species. Composite samples of weathered coal fly ash taken at various depths and fresh coal fly ash were examined using organic petrographic, X-ray diffraction, X-ray fluorescence techniques, and successive extraction procedures. Results obtained show relative enrichment of glass, $\mathrm{Al}-\mathrm{Fe}-$ oxides, calcite, and tridymite in the weathered CFA, but the fresh CFA is enriched in mullite, inertinite, maghemite, and ettringite. The enrichment of the weathered CFA in amorphous glass suggests higher reactivity when compared to fresh CFA. The evident depletion of soluble oxides in the weathered CFA is attributed to flushing of the soluble salts by percolating rainwater. Comparative enrichment of examined elements in watersoluble, exchangeable, reducible, and residual fractions of the weathered CFA is partly due to the slow release of adsorbed chemical species from the alumina-silicate matrix and diffusion from the deeper sections of the particles of coal fly ash. Sodium and potassium show enrichment in the oxidisable fraction of fresh CFA. The estimated mobility factor indicates mobility for $\mathrm{Ca}, \mathrm{Mg}$, Na, Se, Mo, and $\mathrm{Sb}$ and $\mathrm{K}, \mathrm{Sr}, \mathrm{V}, \mathrm{Cu}, \mathrm{Cr}$, Se, and $\mathrm{B}$ in fresh and weathered CFAs, respectively.
\end{abstract}

\section{Keywords}

Weathered ash, Fresh ash, Organic petrography, Sequential extraction, Metal mobility, And mineral transformations 